\title{
The Majority of Complaints About Orthopedic Sports Surgeons on Yelp Are Nonclinical
}

\author{
Jordan R. Pollock, B.S., Jaymeson R. Arthur, M.D., Jacob F. Smith, B.S., Tala Mujahed, B.S., \\ Joseph C. Brinkman, M.D., M. Lane Moore, B.S., and Anikar Chhabra, M.D.
}

\begin{abstract}
Purpose: To examine and characterize extremely negative Yelp reviews of orthopedic sports surgeons in the United States. Methods: A search for reviews was performed using the keywords "Orthopedic Sports Medicine" on Yelp.com for 8 major metropolitan areas. Single-star reviews were isolated for analysis, and individual complaints were then categorized as clinical or nonclinical. The reviews were classified as surgical or nonsurgical. Results: A total of 11,033 reviews were surveyed. Of these, 1,045 (9.5\%) were identified as 1-star, and 289 were ultimately included in the study. These reviews encompassed 566 total complaints, $133(23 \%)$ of which were clinical, and $433(77 \%)$ of which were nonclinical in nature. The most common clinical complaints concerned complications (32 complaints; $6 \%$ ), misdiagnosis (29 complaints; $5 \%)$, and uncontrolled pain (21 complaints; $4 \%$ ). The most common nonclinical complaints concerned physicians' bedside manner (120 complaints; $21 \%$ ), unprofessional staff (98 complaints; 17\%), and finances (78 complaints; 14\%). Patients who had undergone surgery wrote 47 reviews that resulted in 114 complaints (20.5\% of total complaints), whereas nonsurgical patients were responsible for 242 reviews and a total of 452 complaints (81.3\% of total complaints). The difference in the number of complaints by patients after surgery and patients without surgery was statistically significant $(P<0.05)$ for all categories except for uncontrolled pain, delay in care, bedside manner of midlevel staff, and facilities. Conclusion: Our study of extremely negative Yelp reviews found that $77 \%$ of negative complaints were nonclinical in nature. The most common clinical complaints were complications, misdiagnoses and uncontrolled pain. Only 16\% of 1-star reviews were from surgical patients. Clinical Relevance: Patients use online review platforms when choosing surgeons. A comprehensive understanding of factors affecting patient satisfaction and dissatisfaction is needed. The results of our study could be used to guide future quality-improvement measures and to assist surgeons in maintaining favorable online reputations.
\end{abstract}

$\mathbf{O}$ rthopedic sports medicine is a subspecialty of orthopedic surgery that focuses on minimally invasive surgery to address acute as well as degenerative conditions. ${ }^{1}$ It is estimated that high school athletes in the United States alone account for an estimated

From the Mayo Clinic Alix School of Medicine (J.R.P., J.F.S., T.M., M.L.M.), Scottsdale, Arizona; and Department of Orthopedics, Mayo Clinic (J.R.A., J.C.B., A.C.), Phoenix, Arizona, U.S.A.

The authors report the following potential conflicts of interest or sources of funding: AC receives personal fees as a consultant and speakers' bureau member for Arthrex and as a consultant for Zimmer-Biomet. No funding was involved in this study. Full ICMJE author disclosure forms are available for this article online, as supplementary material.

Received February 15, 2021; accepted July 12, 2021.

Address correspondence to Anikar Chhabra, M.D., Mayo Clinic, Department of Orthopedic Surgery, 5881 East Mayo Boulevard, Phoenix, AZ 85054, U.S.A.E-mail:Chhabra.anikar@mayo.edu

(C) 2021 THE AUTHORS. Published by Elsevier Inc. on behalf of the Arthroscopy Association of North America. This is an open access article under the CC BY-NC-ND license (http://creativecommons.org/licenses/by-nc-nd/4.0/).

2666-061X/21156

https://doi.org/10.1016/j.asmr.2021.07.008
2,000,000 injuries in 1 year and 500,000 physician visits. ${ }^{2,3}$ Furthermore, the Centers for Disease Control estimate that nearly 8.6 million sports- and recreationrelated injuries occur each year in the United States. ${ }^{4}$ Considering how such a prevalence of sports injuries affects the U.S. health care system, an appropriate understanding of patient satisfaction and quality outcomes related to their treatment is important.

There has been an increased effort to maximize the value of health care in recent years. High-quality data concerning providers has been publicly available for years; however, the Affordable Care Act encouraged more transparency regarding previously confidential Medicare data concerning use and payments. Additionally, the Hospital Consumer Assessment of Healthcare Providers and Systems (HCAHPS) survey collects patient-reported experiences and aims to increase the quality of hospital care. ${ }^{5}$ Although providers seem to rely on the HCAHPS survey and other standardized metrics, patients also rely on other independent sources for information. ${ }^{6}$ Specifically, $72 \%$ of Americans 
reported using a social media website for health-related consumer reviews, whereas only $6 \%$ of patients were aware of the Hospital Compare website. ${ }^{7,8}$

The use of independent online physician-rating tools is growing in importance in the United States. It has been estimated that $60 \%$ of patients use online physician-rating and review resources when selecting a physician. ${ }^{9}$ The use of online physician-rating platforms has also become more important in light of the recent rise in consumer-centric health insurance plans. ${ }^{10}$ Although there are many online review resources, Yelp.com is perhaps the most widely used resource that patients access when evaluating surgeons. ${ }^{11}$ Websites such as Yelp.com provide a flexible, open-ended response platform where patients can expound important details relating to the entirety of their health care experience, rather than providing a limited, narrow response on a multiple-choice survey.

Research focusing on satisfaction and health care experience with individual providers is lacking. ${ }^{12-14}$ Although orthopedic surgeons generally receive favorable reviews, there exist a considerable number of negative and extremely negative reviews. ${ }^{15}$ In fact, it has been demonstrated that most reviews on crowdsourced websites are at either extreme of the positivenegative spectrum. ${ }^{16}$ As online resources are being increasingly used by patients when choosing surgeons, understanding the factors related to poor reviews is important. The focus of this study was to examine and characterize extremely negative Yelp reviews of orthopedic sports surgeons in the United States. We hypothesized that negative Yelp reviews would focus on nonclinical aspects of care more than on clinical aspects of care.

\section{Methods}

The methods of our study were adapted from a study of extremely negative Yelp reviews of surgeons performing total joint arthroplasty. ${ }^{17}$ In July of 2020, a search for "orthopedic sports medicine" was performed on Yelp.com for 8 major metropolitan cities, including Phoenix, Dallas, New York, Washington, D.C., Seattle, San Francisco, Boston, and Los Angeles. The review was confirmed to be related to an accredited orthopedic sports surgeon through a secondary internet search using vitals.com, physician websites, Angie's list, hospital group websites, and/or Doximity. We excluded reviews of practices consisting of multiple specialties and reviews that did not name a particular surgeon so as to ensure that our study remained focused on reviews of confirmed orthopedic sports surgeons.

After excluding reviews other than l-star (of a possible 5 stars), the complaints were categorized into clinical categories, such as readmissions, treatment complications and reoperation. Complaints were also categorized into nonclinical categories, such as bedside manner, professionalism, waiting time and financial issues. These categories were based largely on another study examining negative Yelp reviews in the field of total joint arthroplasty. ${ }^{17}$ The total number of complaints is larger than the number of reviews because an individual review commonly contains multiple complaints. Reviews were considered surgical or nonsurgical on the basis of whether a surgical episode of care was referenced, and reviews that were unable to be categorized per the above criteria were excluded. The categorization of these variables was performed by medical students to limit potential bias by orthopedic surgeons. Two medical students categorized the data independently, with disagreement being resolved by a third medical student (Fig 1).

Categorical variables were analyzed using the $\chi^{2}$ test with $\alpha$ set at 0.05 . Statistical analysis was performed using a commercially available software package (JMP Pro, version 13, SAS Institute, Cary, NC).

\section{Results}

A total of 11,033 reviews were analyzed, with 1,045 reviews' $(9.5 \%)$ being identified as 1-star. Of these 1star reviews, 756 were excluded because they were not based on an orthopedic sports medicine practice, and 11 were excluded due to unclear classification. In total, 2891 -star reviews were included in the study, comprising 566 total complaints. Of all complaints, 133 $(23 \%)$ were clinically related, and $433(77 \%)$ were nonclinical in nature. The most common clinical complaints concerned complications (32 complaints; 6\%), misdiagnosis (29 complaints; $5 \%$ ), uncontrolled pain (21 complaints; $4 \%$ ), and unclear treatment plans (18 complaints; $3 \%$ ). The most commomn nonclinical complaints concerned physicians' bedside manner (120 complaints; $21 \%$ ), unprofessional staff (98 complaints; $17 \%$ ), finances (78 complaints; $14 \%$ ), and waiting time (63 complaints; 11\%) (Table 1) (Fig 2) (Fig 3).

Patients undergoing surgery were responsible for 47 reviews that resulted in 114 complaints $(20.5 \%$ of total complaints). Of these 114 complaints, $63(55.3 \%)$ were clinical, and $51(44.7 \%)$ were nonclinical in nature. The most common clinical complaints by patients after surgery were complications (26 complaints; $23 \%$ ), reoperations (16 complaints; 14\%), uncontrolled pain (9 complaints; $8 \%$ ), and misdiagnoses (5 complaints; $4 \%)$. The most common nonclinical complaints were bedside manner of the physician (21 complaints; $18 \%$ ), waiting time (8 complaints; $7 \%)$, finances (8 complaints; $7 \%$ ), and unprofessional staff (7 complaints; $6 \%)$.

Patients who had not undergone surgery were responsible for 242 reviews and a total of 452 complaints $(81.3 \%$ of total complaints). Of these 452 complaints, 70 were clinically related, and 382 were nonclinical in nature. The most common clinical 

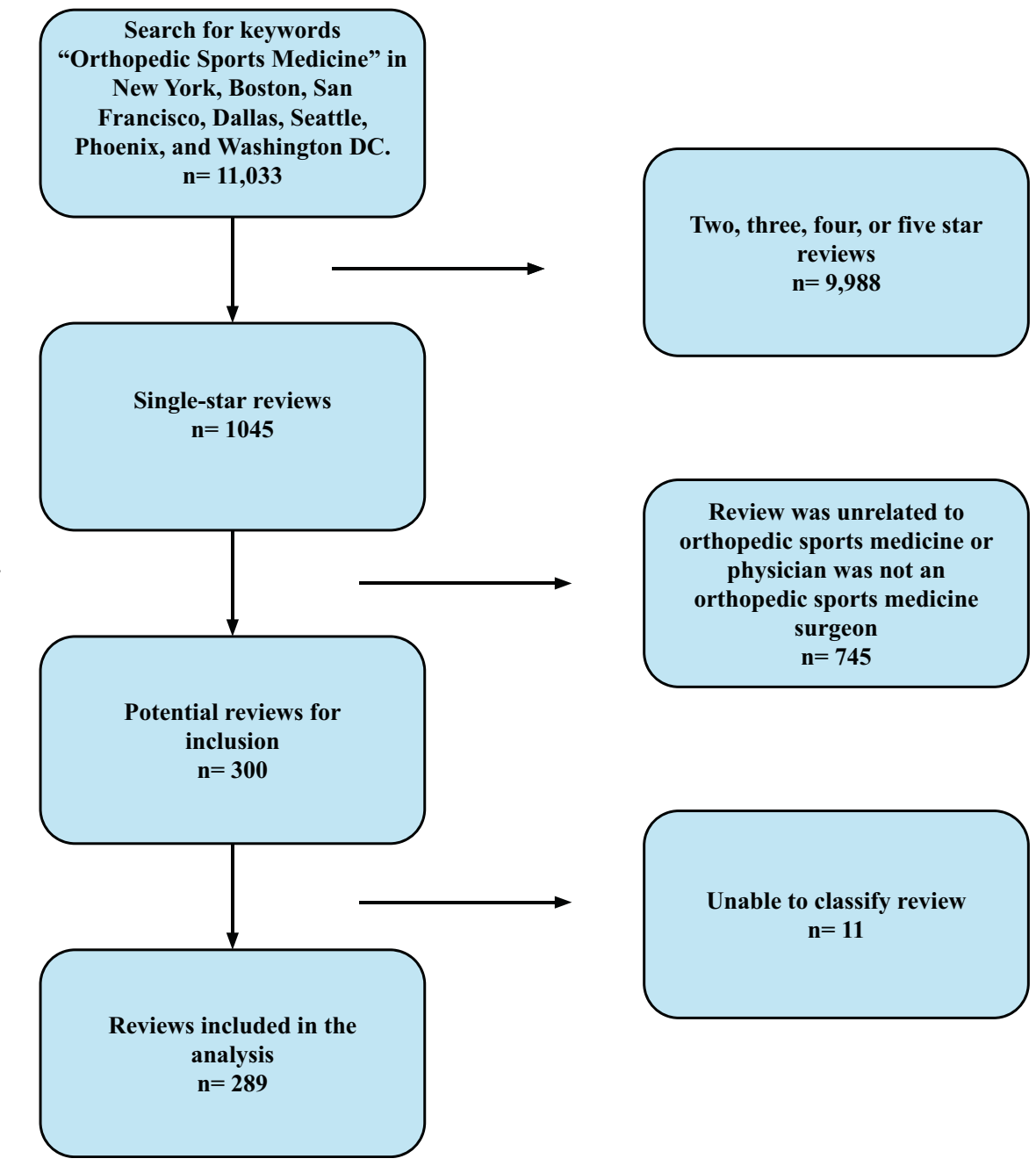

Fig 1. Flowchart for inclusion and exclusion of Yelp reviews in the study.
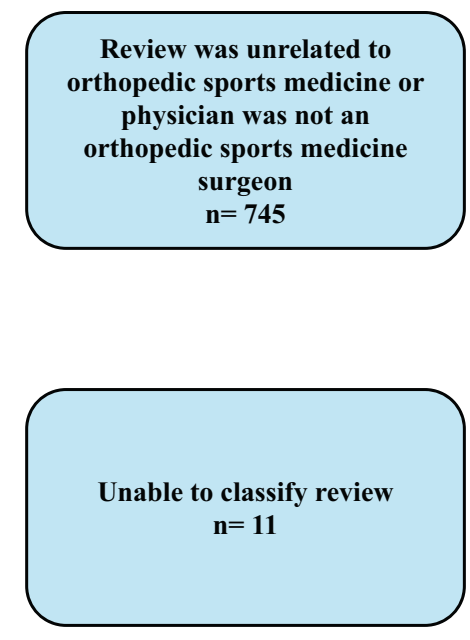

complaints were misdiagnosis (24 complaints; 5\%), unclear treatment plan (14 complaints; 3\%) and uncontrolled pain (12 complaints; $3 \%$ ). The most common nonclinical complaints for patients without surgery were for bedside manner (99 complaints; $22 \%$ ), unprofessional staff (91 complaints; $20 \%$ ) and finances (70 complaints; $15 \%)$. The difference in the number of complaints by patients with and without surgery was statistically significant $(P<0.05)$ for all categories with the exception of uncontrolled pain, delay in care, bedside manner, and facilities (Table 2) (Fig 4).

\section{Discussion}

Nonclinical complaints were more than 3 times more common than clinical complaints in the extremely negative reviews of orthopedic sports surgeons found on Yelp.com. The most frequently cited nonclinical complaints were related to physicians' bedside manner, unprofessional staff, finances, and waiting times. The most common clinical complaints were related to complications, misdiagnoses, uncontrolled pain, and reoperation. These findings are similar to those of other studies, in which nonclinical complaints are more common than clinical complaints. ${ }^{17-19}$ Although our study has limitations, we believe the information it contains is relevant and important for orthopedic sports surgeons as they aim to increase patient satisfaction, improve patient care and provide high-value care.

These results coincide with previous reports that nonclinical complaints, such as waiting times, interactions with office staff and other nonclinical characteristics are common sources of patients' complaints about physicians. ${ }^{20-22}$ The most common complaint in our study was physicians' bedside manner, accounting for $21 \%$ of all complaints. Interestingly, studies have demonstrated that bedside manner is likely to be the most important factor in patient satisfaction, with improvement in bedside manner correlating with the greatest increase in patient satisfaction. ${ }^{15,23}$ A survey of patients' views of physicians noted that patients are more focused on doctor-patient relationships than on health care delivery and health outcomes. ${ }^{24}$ Communication ratings have also been found to have more 
Table 1. Analysis of Negative Yelp Reviews Categorized as Clinical And Nonclinical Complaints

\begin{tabular}{|c|c|c|}
\hline Focus of the Review & $\begin{array}{c}\text { Number of } \\
\text { Complaints, } \\
\text { N (\% of Total) }\end{array}$ & $\begin{array}{c}\text { Percentage of } \\
\text { Responses } \\
\text { within Category }\end{array}$ \\
\hline Clinical Complaints & & $\begin{array}{c}\text { Clinical } \\
\text { Category } \\
(\mathrm{N}=133 \\
\text { complaints })\end{array}$ \\
\hline Complication & $32(6 \%)$ & $24 \%$ \\
\hline Misdiagnosis & $29(5 \%)$ & $22 \%$ \\
\hline Uncontrolled pain & $21(4 \%)$ & $16 \%$ \\
\hline Reoperation & $18(3 \%)$ & $14 \%$ \\
\hline Unclear treatment plan & $15(3 \%)$ & $11 \%$ \\
\hline Delay in care & $14(2 \%)$ & $11 \%$ \\
\hline Readmission & $4(1 \%)$ & $3 \%$ \\
\hline Total Complaints & 133 & \\
\hline Nonclinical complaints & & $\begin{array}{c}\text { Nonclinical } \\
\text { Category } \\
(\mathrm{N}=433 \\
\text { complaints) }\end{array}$ \\
\hline Physician bedside manner & $120(21 \%)$ & $28 \%$ \\
\hline Unprofessional staff & $98(17 \%)$ & $23 \%$ \\
\hline Financially related & $78(14 \%)$ & $18 \%$ \\
\hline Wait time & $63(11 \%)$ & $15 \%$ \\
\hline Scheduling issues & $29(5 \%)$ & $7 \%$ \\
\hline $\begin{array}{l}\text { Not enough time spent } \\
\text { with provider }\end{array}$ & $26(5 \%)$ & $6 \%$ \\
\hline $\begin{array}{l}\text { Bedside manner } \\
\text { midlevel }\end{array}$ & $12(2 \%)$ & $3 \%$ \\
\hline Facilities & $7(1 \%)$ & $2 \%$ \\
\hline Total complaints & 433 & \\
\hline
\end{tabular}

influence on patient satisfaction than quality of care. ${ }^{25}$ Our findings are further contextualized by these studies that underscore the importance of qualitative characteristics in patient ratings.
In our study we found that only $2 \%$ of reviews complained of midlevel providers, whereas $17 \%$ focused on unprofessional staff, and $21 \%$ focused on physicians. A recent article examining patients' perspectives of midlevel providers in orthopedic sports found that $62.9 \%$ of patients reported that a physician's midlevel provider is an important consideration when choosing a physician. ${ }^{26} \mathrm{~A}$ recent study of 11,527 reviews by patients of total joint arthroplasty surgeons found that higher ratings of orthopedic surgeons were significantly correlated with staff friendliness, punctuality and knowledge/expertise. ${ }^{27}$ Therefore, because modern orthopedic patient care has become an interdisciplinary team approach, with responsibilities shared among nurses, office staff, medical assistants, midlevel providers, and the attending physician, ratings of physicians are often a reflection of an entire team of individuals, not just of a single provider. Our results support this notion; a substantial number of negative reviews of orthopedic sports surgeons were associated with interactions with midlevel and office staff rather than with the surgeon.

Of the 566 complaints in our study, there were 78 (14\%) financial complaints relating to insurance issues, billing problems or excessive cost. This coincides with a previous report that nearly 1 in 6 patients undergoing elective orthopedic surgery is potentially at risk for a surprise bill. ${ }^{28,29}$ It is important to understand these finance-related issues bscause they are a common source of complaints for orthopedic surgeons. A study of 1,077 patients involved in orthopedic sports medicine found that being an in-network provider was, predictably, 1 of the most important factors for patients when choosing an orthopedic sports medicine physician. ${ }^{10}$ In addition, patients who receive accurate

\section{Clinical Complaints of Orthopedic Sports Medicine Patients}

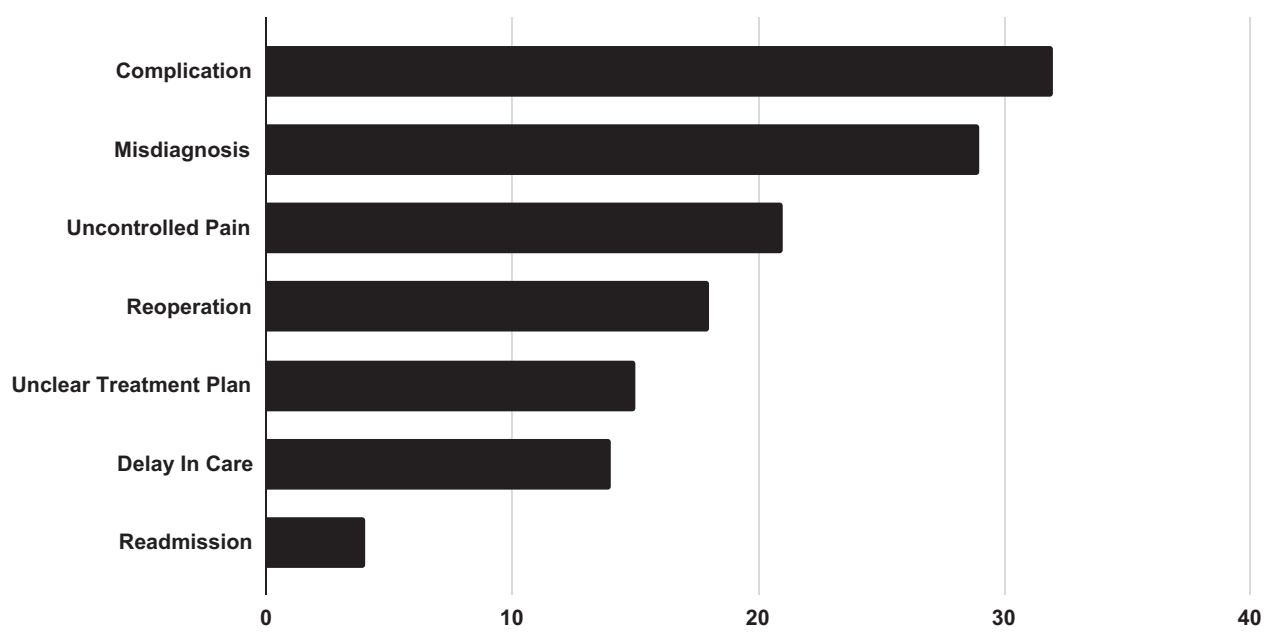

Fig 2. The most common clinical complaints on Yelp.com of patients undergoing orthopedic sports medicine surgery. 


\section{Non-Clinical Complaints of Orthopedic Sports Medicine Patients}

Fig 3. The most common clinical complaints on Yelp.com of all patients of orthopedic sports medicine surgeons. This figure defines non-clinical complaints among all orthopedic patient reviews included in this study.

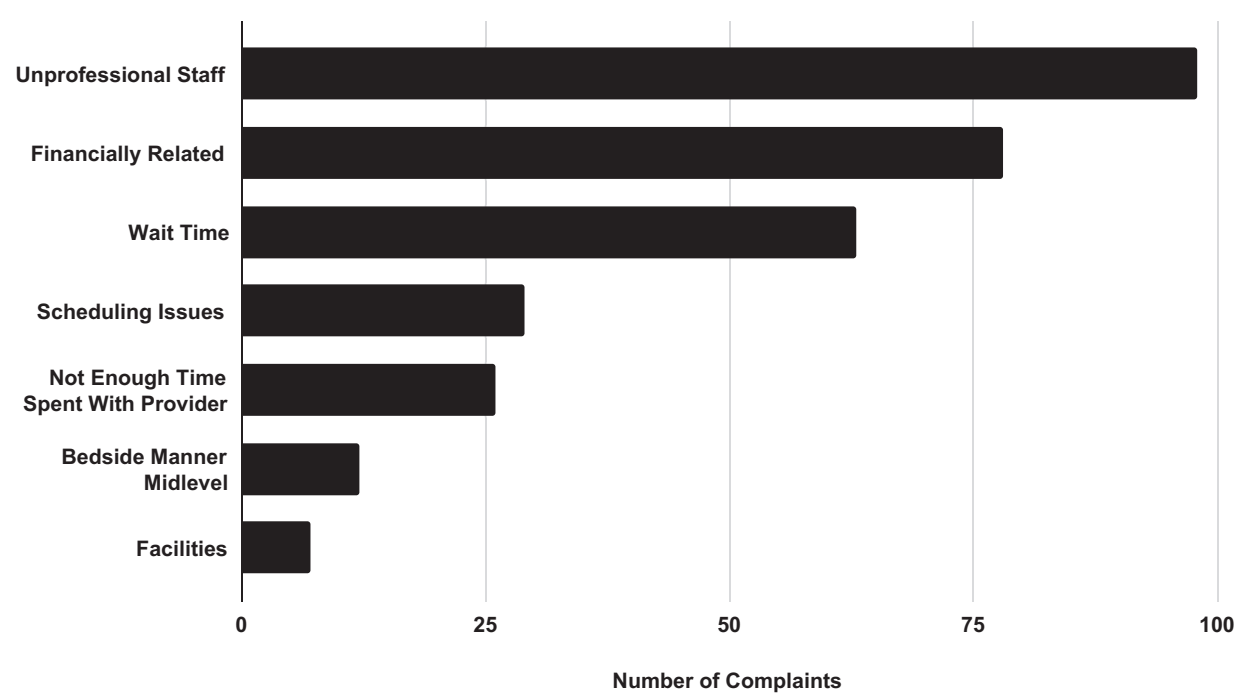

information about the cost of care are more likely to rate positively the quality of the care they receive. ${ }^{24} \mathrm{~A}$ study examining patients' perspectives on cost reported that $48 \%$ of patients expected physicians to initiate a conversation about the costs of care for treatment. Alternatively, only $7 \%$ of patients actually discussed the costs of their surgical care with their physicians. ${ }^{30}$ Our results regarding financially related concerns suggest that discussing the cost of various treatment options could help to improve patient satisfaction and to decrease the number of negative reviews.
Although clinical complaints were less common than nonclinical complaints, they are still noteworthy because they accounted for almost a quarter of the extremely negative reviews in our study. A substantial number of clinical complaints regarding complication, misdiagnosis, uncontrolled pain, and reoperation were reported. This is somewhat to be expected because a study of knee arthroscopy found that the overall incidence of complication was about $2 \%$, with major complications about $0.9 \% .^{31}$ Although complications are somewhat common, not all of these complications

Table 2. Analysis of Negative Yelp Reviews Categorized as Clinical or Nonclinical Complaints by Patients With or Without Surgery

\begin{tabular}{|c|c|c|c|}
\hline & Surgical Patients $(\mathrm{N}=47)$ & Nonsurgical Patients $(\mathrm{N}=242)$ & \\
\hline Complication & $26(23 \%)$ & $6(1 \%)$ & $<0.001$ \\
\hline Reoperation & $16(14 \%)$ & $2(0 \%)$ & $<0.001$ \\
\hline Uncontrolled pain & $9(8 \%)$ & $12(3 \%)$ & 0.326 \\
\hline Misdiagnosis & $5(4 \%)$ & $24(5 \%)$ & 0.012 \\
\hline Unclear treatment plan & $1(1 \%)$ & $14(3 \%)$ & $<0.001$ \\
\hline Total complaints & 63 & 70 & \\
\hline \multicolumn{4}{|l|}{ Nonclinical } \\
\hline Bedside manner, doctor & $21(18 \%)$ & $99(22 \%)$ & $<0.001$ \\
\hline Wait time & $8(7 \%)$ & $55(12 \%)$ & $<0.001$ \\
\hline Finance related & $8(7 \%)$ & $70(15 \%)$ & $<0.001$ \\
\hline Facilities & $0(0 \%)$ & $7(2 \%)$ & 0.022 \\
\hline Total complaints & 51 & 382 & \\
\hline
\end{tabular}

NOTE. Numbers in bold indicate significant differences between surgical and non-surgical complaints. 


\section{Surgical Patient Complaints vs. Non-Surgical Patients Complaints}

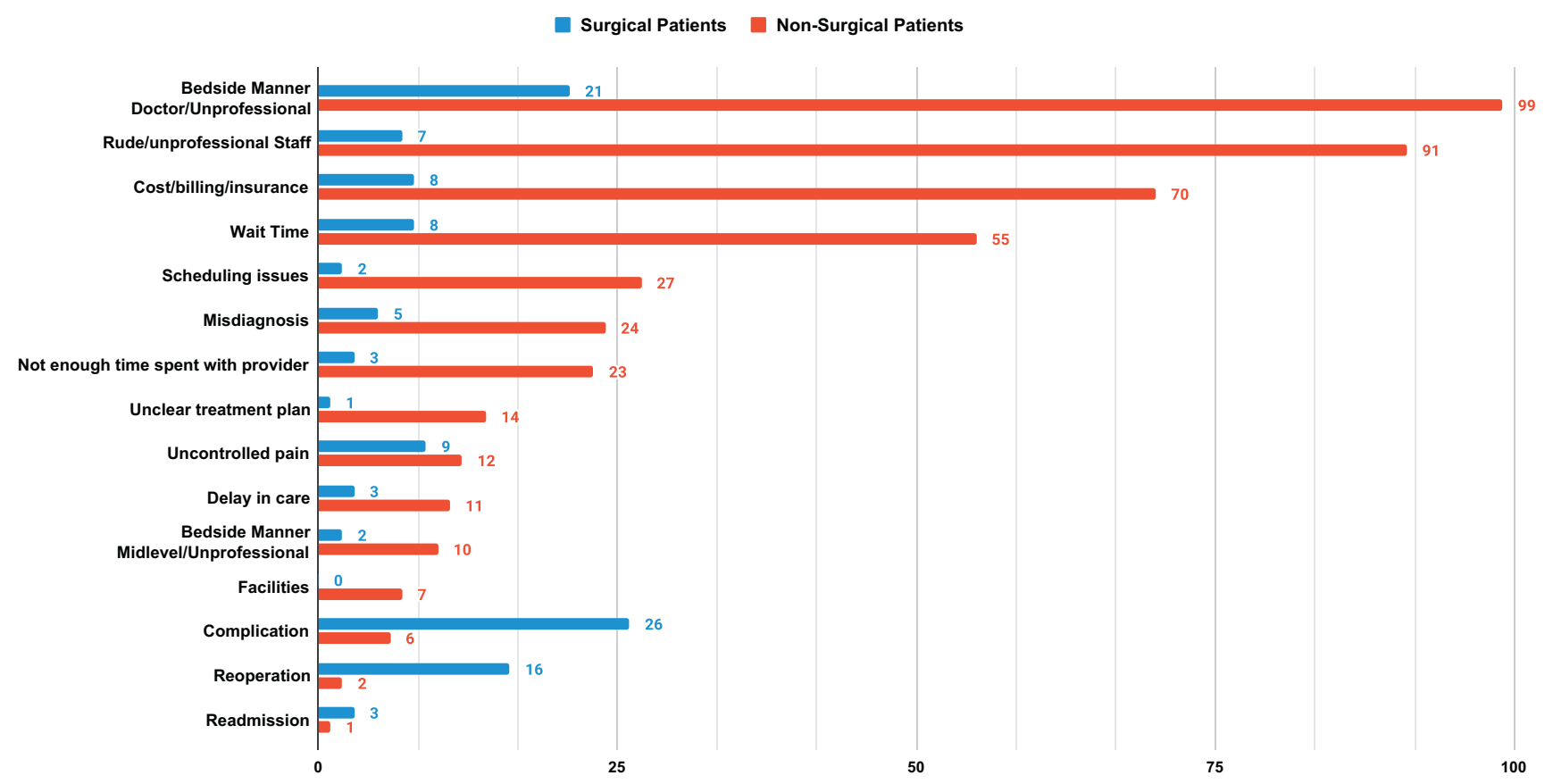

Number of Complaints

Fig 4. Comparison of complaints by patients who reported having surgery versus patients who did not report having surgery.

should result in extremely negative reviews. Complications and poor outcomes are always a risk of surgery, so education and establishing appropriate expectations prior to surgery may help patients to become better satisfied with their care. ${ }^{32,33}$

It remains unclear whether the information available in online review and rating websites reflects the quality of care accurately. Several previous studies have attempted to assess the relationship that online reviews share with readmission rates, infections, morbidity, mortality, and infection. These results have demonstrated a consistently poor association between online ratings and objective health care outcome measures. $^{34-36}$ In our study, $77 \%$ of all complaints were related to nonclinical issues, suggesting that the majority of negative online reviews are separate from factors that are directly related to the quality or outcome of the care received. This suggests that, similar to previous investigations in other subspecialties, orthopedic sports surgeon reviews demonstrate a poor correlation between online ratings and objectively measurable patient outcomes.

The characterization and volume of complaints were significantly different between patients who underwent surgery and those who did not. After surgery, patients were responsible for only about $16 \%$ of the 1-star reviews on Yelp, whereas patients without surgery accounted for $84 \%$ of the 1 -star reviews. This could be a result of a significantly positive correlation between patients requiring surgery and patient satisfaction. ${ }^{37}$ Alternatively, patients with extremely negative preoperative interactions would be unlikely to proceed with surgery.

The factors most commonly cited in extremely negative Yelp.com reviews of orthopedic sports surgeons are related to physicians' bedside manner, unprofessional staff, finances, and waiting times. An understanding of factors leading to extremely negative reviews on social media platforms is necessary for orthopedic sports surgeons to improve patient satisfaction and maintain positive reputations. The results of our study and further context surrounding patient satisfaction can be used to direct quality-improvement projects aimed at bettering patients' experiences.

\section{Limitations}

Our study has several limitations. Only Yelp.com reviews were analyzed in our study, and our results should be understood in that context. For example, it has been reported that patients who are either extremely satisfied or extremely dissatisfied with their care are most likely to leave reviews. The patients writing the extremely negative reviews found on Yelp.com may not be representative of surgeons' practices. There could also be patients who are extremely dissatisfied with their care but do not report this dissatisfaction on Yelp.com. The search of Yelp.com reviews consisted of 8 large metropolitan areas, albeit in vastly different geographic areas; nonetheless, 
that could limit the applicability of our findings to surgeons in rural areas. It is also possible that the reviews analyzed in our study were erroneously categorized. However, we had 2 authors independently categorize these variables, and any differences were subsequently resolved by a third author.

\section{Conclusion}

Our study of extremely negative Yelp reviews found that $77 \%$ of negative complaints were nonclinical in nature. The most common clinical complaints were complications, misdiagnosis and uncontrolled pain. Only $16 \%$ of 1 -star reviews were by patients who had undergone surgery.

\section{References}

1. Vasta S, Papalia R, Albo E, et al. Top orthopedic sports medicine procedures. J Orthopaed Surg Res 2018;13:190.

2. Sports-related injuries among high school athletes: United States, 2005-06 school year, https://www.cdc.gov/mmwr/ preview/mmwrhtml/mm5538al.htm. Accessed January 17, 2021

3. Patel DR, Yamasaki A, Brown K. Epidemiology of sportsrelated musculoskeletal injuries in young athletes in United States. Transl Pediatr 2017;6:160-166.

4. National Health Statistics Reports, Number 99. November 18, 2016. 2016;12.

5. Giordano LA, Elliott MN, Goldstein E, et al. Development, implementation, and public reporting of the HCAHPS survey. Med Care Res Rev 2010;67:27-37.

6. Holliday AM, Kachalia A, Meyer GS, et al. Physician and patient views on public physician rating websites: A crosssectional study. J Gen Intern Med 2017;32:626-631.

7. PricewaterhouseCoopers. Social media 'likes' healthcare: From marketing to social business. PwC, https://Www. pwc.com/us/en/industries/health-industries/library/healthcare-social-media.html. Accessed December 30, 2020.

8. Sep 30 P, 2008. 2008 Update on consumers' views of patient safety and quality information. KFF, https://www. kff.org/health-reform/poll-finding/2008-update-on-consumers-views-of-patient-2/ 2008. Accessed December 30,2020 .

9. Hanauer DA, Zheng K, Singer DC, et al. Public awareness, perception, and use of online physician rating sites. JAMA 2014;311:734.

10. Manning BT, Bohl DD, Saltzman BM, et al. Factors influencing patient selection of an orthopaedic sports medicine physician. Orthop J Sports Med 2017;5. doi:10.1177/ 2325967117724415 . Epub ahead of print, August 22.

11. Ziemba JB, Allaf ME, Haldeman D. Consumer Preferences and Online Comparison Tools Used to Select a Surgeon. JAMA Surg 2017;152:410.

12. Reimann S, Strech D. The representation of patient experience and satisfaction in physician rating sites. A criteria-based analysis of English- and German-language sites. BMC Health Serv Res 2010;10:332.

13. The Cost of Satisfaction: A National Study of Patient Satisfaction, Health Care Utilization, Expenditures, and Mortality | Geriatrics | JAMA Internal Medicine | JAMA
Network, https://jamanetwork.com/journals/jamainternal medicine/fullarticle/1108766. Accessed December 30, 2020 .

14. Burkle CM, Keegan MT. Popularity of internet physician rating sites and their apparent influence on patients' choices of physicians. BMC Health Services Research 2015;15:416.

15. Bakhsh W, Mesfin A. Online ratings of orthopedic surgeons: analysis of 2185 reviews. Am J Orthop (Belle Mead NJ) 2014;43:359-363.

16. Frost C, Mesfin A. Online Reviews of Orthopedic Surgeons: An Emerging Trend. ORTHOPEDICS 2015;38: e257-e262.

17. Arthur JR, Etzioni D, Schwartz AJ. Characterizing extremely negative reviews of total joint arthroplasty practices and surgeons on yelp.com. Arthroplast Today 2019;5:216-220.

18. King JD, van Dijk PAD, Overbeek CL, et al. Patient complaints emphasize non-technical aspects of care at a tertiary referral hospital. Arch Bone Jt Surg 2017;5:74-81.

19. Ha JF, Longnecker N. Doctor-patient communication: A review. Ochsner J 2010;10:38-43.

20. Emmert M, Meier F, Heider A-K, et al. What do patients say about their physicians? An analysis of 3000 narrative comments posted on a German physician rating website. Health Policy 2014;1 18:66-73.

21. López A, Detz A, Ratanawongsa N, et al. What Patients say about their doctors online: A qualitative content analysis. J Gen Intern Med 2012;27:685-692.

22. Gao GG, McCullough JS, Agarwal R, et al. A changing landscape of physician quality reporting: Analysis of patients' online ratings of their physicians over a 5-year period. J Med InterRes 2012;14:e38.

23. Aa U, Ft C, Sr F, et al. The relationship between physician friendliness and caring, and patient satisfaction: Findings from an internet-based survey. Patient 2008;1:91-96.

24. Finding quality doctors: How Americans evaluate provider quality in the United States. AP-NORC, https:// apnorc.org/projects/finding-quality-doctors-how-americansevaluate-provider-quality-in-the-united-states/. Accessed January 7, 2021.

25. Chang JT, Hays RD, Shekelle PG, et al. Patients' global ratings of their health care are not associated with the technical quality of their care. Ann Intern Med 2006;144: 665.

26. Manning BT, Bohl DD, Hannon CP, et al. Patient perspectives of midlevel providers in orthopaedic sports medicine. Orthop J Sports Med 2018;6. doi:10.1177/ 2325967118766873 . Epub ahead of print, April 10.

27. Yu J, Samuel LT, Yalçin S, et al. Patient-recorded physician ratings: What can we learn from 11,527 online reviews of orthopedic surgeons? J Arthroplast 2020;35: S364-S367.

28. Dekhne MS, Nuliyalu U, Schoenfeld AJ, et al. "Surprise" out-of-network billing in orthopedic surgery: Charges from surprising sources. Ann Surg 2020;271:el16.

29. Bluth R. 1 In 6 insured hospital patients get a surprise bill for out-of-network care. Kaiser Health News, https://khn. org/news/ 1 -in-6-insured-hospital-patients-get-a-surprisebill-for-out-of-network-care/ 2019. Accessed January 4, 2020 . 
30. Alokozai A, Crijns TJ, Janssen SJ, et al. Cost in hand surgery: The patient perspective. J Hand Surg 2019;44: 992. el-992.e26.

31. Degen RM, Lebedeva Y, Birmingham TB, et al. Trends in knee arthroscopy utilization: A gap in knowledge translation. Knee Surg Sports Traumatol Arthrosc 2020;28:439-447.

32. Trojan JD, DeFroda SF, Mulcahey MK. Patient understanding, expectations, outcomes, and satisfaction regarding surgical management of shoulder instability. Phys Sportsmed 2019;47:6-9.

33. Rosenberger PH, Jokl P, Cameron A, et al. Shared decision making, preoperative expectations, and postoperative reality: Differences in physician and patient predictions and ratings of knee surgery outcomes. Arthroscopy 2005;21: 562-569.
34. Murphy GP, Radadia KD, Breyer BN. Online physician reviews: Is there a place for them? Risk Manag Healthc Policy 2019;12:85-89.

35. Trehan SK, Nguyen JT, Marx R, et al. Online patient ratings are not correlated with total knee replacement surgeon: Specific outcomes. HSS J 2018;14:177-180.

36. Journal of Medical Internet Research. Web-based physician ratings for California physicians on probation, https://www.jmir.org/2017/8/e254/. Accessed April 20, 2021.

37. Factors associated with patient satisfaction scores for physician care in trauma patients. J Trauma Acute Care Surg, https://journals.lww.com/jtrauma/Abstract/2013/ 07000/Factors_associated_with_patient_satisfaction.19. aspx. Accessed January 3, 2021. 